The entire work is a most valuable contribution to the reference books on Organic Chemistry and no laboratory can well afford to be without a copy. CHAS. BAskerville.

UNIVERSITY OF NORTH CAROLINA, September 30, 1899.

The Rise and Development of the Liquefaction of Gases. By Willett L. Hardin, Ph.D. Macmillans, 1899. 8 vo. $250 \mathrm{pp}$.

Written from a historical point of view and with an ample command of the subject, this book of Dr. Hardin's is really a very satisfactory compilation: It is prepared with evident care and industry, and is finely illustrated. Why a 'popular-science style,' in which it professes to be written, should differ at times from good English, is not plain to the reviewer: but this is the severest criticism that need be made.

The author limits himself to a record of the statements of others, and he is therefore responsible chiefly for the selection and arrangement of his material. Here we might wish that the researches upon the more readily condensable gases, preceding the achievements of Cailletet and Pictet, had been treated more concisely, in order that more room had been found, toward the end of the book, for the discussion of the utilization of liquid air, etc., as at present proposed. The treatment of the latter topic is very scanty, in view of the fact that probably four out of five of the prospective purchasers of the book are interested in the uses of liquefied gases, rather than in the methods of their production. Two chapters, involving thermodynamics, would seem forbidding to the nontechnical reader, while they bring no new information to the chemist or physicist. If they could be made the basis of a new chapter, discussing the economic value of gas-liquefaction, for commercial refrigeration and for the intensification of the potential energy of engines, they would serve a most useful purpose.

\section{MORRIS LOEB.}

\section{BOOKS RECEIVED.}

The Compendious Manual of Qualitative Chemical Analysis. C. W. Eliot and F. H. Storer. Newly revised by W. B. LiNDSAY and F. H. STORER. New York, D. Van Nostrand Company. 1899. Pp. vii + 202. $\$ 1.25$.
The Evolution of General Ideas. Tн. Rгвот. Translated by Frances A. Werby. Chicago, Open Court Publishing Company. 1899. Pp. xi +231 . \$1.25.

Wabeno, the Magician. MABeL Osgood Wright. New York and London, The Macmillan Company. 1899. Pp. $x i+346$. $\$ 1.50$.

\section{SOCIETIES AND ACADEMIES.}

THE ACADEMY OF SCIENCE OF ST. LOUIS.

AT the meeting of the Academy of Science at St. Louis, held on the evening of October 16th, a paper by Dr. T. J. J. See, on the temperature of the sun and the relative ages of the stars and nebulæ, was presented in abstract by Professor Nipher.

The author reviews the work of Helmholtz on the condensation of a homogeneous sun and finds that the heat developed in gravitational condensation from an infinite volume to its present size would be sufficient to heat an equal mass of water about 27 million degrees. In condensing to a mass whose radius was equal to the radius of Neptune's orbit, only about 1 / 6600 part was produced as has been produced since. Nearly all of the heat has been developed since the primitive nebula has reached the dimensions of the solar system. The heat developed before the nebula came within the orbit of Mercury, is only about 1/85 part of the total heat produced up to the present time. If the sun should contract $1 / 10000$ part of its present radius, $69,700 \mathrm{M}$., assuming it to be homogeneous, the heat would raise the temperature of an equal mass of water $2,725 \mathrm{de}-$ grees. The effect of the various planets is considered, and is shown to be insignificant. An annual shrinkage of 35 meters a year would account for the present heat and would effect the radius less than $1 / 10^{\prime \prime}$ in 1,000 years. The fact that ancient and modern eclipses are sen. sibly of the same duration, in connection with the substantial constancy of the moon's mean distance, shows that no considerable alteration of the sun's diameter has occurred in historical time. The essential constancy of solar radiation during the last 2,000 years is well established by the agreement of plant distribution now with that described by Pliny and Theophrastus.

Dr. See then takes up the case of a hetero- 
geneous sphere made up of layers of uniform density, but increasing in density towards the center.

The radiation as at present determined is assumed to apply to all time past and present, and the density is assumed to vary from center to circumference, in accordance, with Lane's deductions in 1870 , the value of $\dot{K}$, the ratio of the two specific heats being 1.4 .

Lane found the density at the center to be 23 times that of water, and by a different process, Kelvin has found it to be 32 times that of water.

Assuming a surface temperature of 8,000 degrees, as found experimentally by Wilson and Gray, the temperature at the center comes out 256,000 degrees $\mathrm{C}$.

The potential of the heterogeneous sun thus assumed is then found by mechanical integration, by dividing the radius into 40 parts, the density of each shell being constant.

The energy developed by the falling together of the parts of this heterogeneous sun is greater than for the homogeneous sun of Helmholtz in the ratio of 176 to 100 . As in the past history of the Helmholtz sun, the radiation would have dissipated this heat at the present rate of radiation in 18 million years, it follows that if the Helmholtz sun "should pass into the heterogeneous sun, discussed by see, by inward gravitation of particles, the past history is increased by about 14 million years. This augmentation of its past is at the expense of its future duration.

The author gives reasons for thinking that condensation cannot go on unchecked by molecular forces after the radius has shortened to much over one-half its present length, and assigns 36 million years as a fair value for the total life of the sun from the time its radius was that of Neptune's orbit to the time when its radiation will become insignificant. Of this total period 32 million years, or $8 / 9$ of the whole, have already elapsed, leaving four million years for a fair estimate of its future duration, with the conditions assumed.

There is reason to believe that under the immense temperatures existing in the sun, the gaseous mass may be so dissociated that all gases behave like monatomic gases. This would increase the ratio of specific heat at constant pressure to that of constant volume from 1.4 to 1.66. This changes the law of density and temperature along the radius. The density at the center becomes much less and the potential of the whole mass upon itself is correspondingly less exhausted. It increases the probable future life of the sun from four to 13 millions of years, and diminishes its past history from 32 to 23 million years. The author concludes that life as it now exists on the earth cannot be maintained longer than three million years, and after five or ten million years, the planet will have become a rigid and lifeless mass.

Dr. H. von Schrenk presented some notes on Arceuthobium pusillum which was found in Maine, during the past summer, growing on the white spruce along the sea-coast. The trees which are attacked form large witches' brooms, the branches of which are much longer than the normal branches. The manner in which the seeds are distributed was briefly described, and seeds were exhibited adhering to branches of the white spruce.

$$
\begin{aligned}
& \text { William Trelease, } \\
& \text { Recording Secretary. }
\end{aligned}
$$

\section{WASHINGTON CHEMICAL SOCIETY.}

The regular meeting was held May 11, 1899.

The first paper of the evening was read by Professor F. W. Clarke and was entitled: 'Experiments on the Constitution of Certain Silicates,' by F. W. Clarke and George Steiger.

The paper cited some results obtained by Clarke and Schneider in 1889-92. The present work led to the following conclusions :

1. That pectolite is a metasilicate.

2. That the formula for pyrophyllite is possibly that of a basic di-metasilicate.

3 . That calamine is probably a basic metasilicate which is in accord with the accepted formula.

With analcite a very interesting ammonia compound was formed, by heating with ammonium chloride. Other experiments agreed closely with those made by Friedel and it was concluded that this mineral is a mixture of ortho- and tri-silicates.

The last paper of the evening was ready by Dr. H. N. Stokes and was entitled: 'Indexing Organic Compounds.' 
Mr. Chesnut exhibited utensils used by the Indian women in the preparation of acorn meal. William H. KRUG, Secretary.

\section{ASTRONOMICAL NOTES.}

CLOCK RATES AND BAROMETRIC PRESSURE,

Ensign Everett Hayden, U. S. Navy, publishes in the Publications of the Astronomical Society of the Pacific, No. 68, an interesting investigation of the effect of variations in barometric pressure upon the rates of clocks and chronometers. This study was made at the Mare Island Observatory, where chronometers are rated for the U.S. Navy, and where the time observations are regularly made, which are supplied by the Western Union Telegraph Company to that part of the country west of Ogden, Utah. The paper gives in detail the results for the Mean Time Clock of the observatory and for three Negus chronometers. The method is empirical, depending upon the rates actually observed under varying pressure and temperature, and the numerical results are obtained graphically. From tests of the Mean Time Clock extending through two hundred days, it is believed that had the rate-curves been used without any time observations the errors of the noon signal would at no time have exceeded six-tenths of a second, and seldom have exceeded one-tenth of a second, and at the end of the period would have been correct within a few hundredths of a second. The barometric and temperature curves of the sidereal and mean time clocks are now used in the current work of the observatory, and the author is of the opinion that a first rate pendulum clock is a much better instrument than usually supposed, and actually comparable in uniformity with the axial rotation of the earth, if account is taken of these variations. The experiments on chronometers lead the author to believe that the use of a barometric curve in actual practice at sea is worthy of trial, and the navigator of one of our naval vessels now in the Pacific will report upon his experience with the three chronometers whose rates are discussed in the paper.

STELLAR PARALLAX BY PHOTOGRAPHY.

A CONTRIBution to this subject is made by
Östen Bergstrand of the observatory at Upsala. The author discusses the theory of the reduction of measures on the photographic plates and the instrumental errors of the Repsold apparatus employed. The parallax of $\Sigma 1516 \mathrm{~A}$ is found to be $0 .{ }^{\prime \prime} 080 \pm 0 .{ }^{\prime \prime} 011$ and of $A-O e$. 11677 , which has a proper motion of nearly $3^{\prime \prime}$, to be $0 . .^{\prime \prime} 192 \pm 0 . .^{\prime \prime} 013$. These determinations were made on account of the discrepancies in the results of other observers. The paper is in Swedish but an abstract in French is supplied.

\section{JUPITER'S FIFTH SATELLITE.}

Professor BARNARD has added to our knowledge of the period of this satellite the results of his observations in the last two oppositions of Jupiter made with the 40 .inch equatorial of of the Yerkes Observatory. Combining these with the earlier observations at the Lick Observatory, the period is $11 \mathrm{~h} .57 \mathrm{~min} .22 .647$ sec. and is not in error exceeding $0.01 \mathrm{sec}$. The discordancies in the separate determinations are very small and the measures show the great accuracy attainable in micrometric observations with these large refractors upon difficult objects. WINSLOW UPTON.

Providence, R. I., Oct. 14, 1899.

\section{CURRENT NOTES ON METEOROLOGY.} KITE AND BALLOON METEOROLOGY IN FRANCE.

Two communications have been made to the French Academy of Sciences during the past summer by Teisserenc de Bort on the kite and balloon work carried on at the Observatory of Trappes. Altitudes of $3,940,3,590$ and 3,300 meters were reached on June 14th, June 15th, and July $3 d$, respectively. The results obtained by means of the kite meteorographs during more than 100 ascents show that in anti-cyclones the rate of decrease of temperature aloft becomes slower at a distance of a few hundred meters above the ground, and inversions of temperature are often observed. In cyclonic areas the decrease of temperature is more rapid. In fine weather, with high pressure, the wind velocity generally decreases with increasing distance from the ground up to an altitude between 1,500 and 3,000 meters. On the other hand, on cloudy days, with low pressure, the velocity 